\title{
BMJ Open 'It all dials back to safety': A qualitative study of social and economic vulnerabilities among transgender women participating in HIV research in the USA
}

To cite: Reisner SL, Chaudhry A, Cooney E, et al. 'It all dials back to safety': A qualitative study of social and economic vulnerabilities among transgender women participating in HIV research in the USA. BMJ Open 2020;10:e029852. doi:10.1136/ bmjopen-2019-029852

- Prepublication history and additional material for this paper are available online. To view please visit the journal (http:// dx.doi.org/10.1136/bmjopen2019-029852).

Received 04 March 2019 Revised 01 October 2019 Accepted 01 November 2019

D Check for updates

(c) Author(s) (or their employer(s)) 2020. Re-use permitted under CC BY-NC. No commercial re-use. See rights and permissions. Published by BMJ.

${ }^{1}$ General Pediatrics, Boston Children's Hospital, Boston, Massachusetts, USA

${ }^{2}$ Epidemiology, Johns Hopkins University Bloomberg School of Public Health, Baltimore, Maryland, USA

${ }^{3}$ Centro de Promoción y Defensa de los Derechos Sexuales y Reproductivos, Lima, Peru

Correspondence to Dr Sari L Reisner;

Sari.Reisner@childrens.harvard. edu

\section{ABSTRACT}

Objectives Transgender women (TW) are highly burdened by HIV infection in the USA. Research is needed into drivers of the HIV epidemic for TW, including longitudinal studies to identify risks for incident HIV infection and optimal intervention targets. This formative research sought to understand TW's experiences with, perceptions of and barriers and facilitators to HIV research participation to inform future research implementation.

Design Between August 2017 and January 2018, five online synchronous computer-mediated focus groups were conducted in English and two in Spanish. Recruitment used a mixed format of technology, such as geotargeted social media, and non-technology infused methods, such as peer referrals. Maximum variation sampling was used to enrol participants across a wide range of characteristics. Qualitative codes were iteratively developed and applied to focus group discussion transcripts by independent analysts.

Setting Participants were recruited from Atlanta, Baltimore, Boston, Miami, New York City and Washington D.C.

Participants Participants identified as TW $\geq 18$ years and resided in one of the six metropolitan areas or outlying regions. 33 participants elected to partake in English focus groups and eight participated in Spanish-led groups. Results The geographically diverse sample had a mean age of 41.1 years $(S D=13.6)$, and $34 \%$ identified as Black African American and $29 \%$ as Hispanic/Latina. Social and economic factors were found to shape HIV research participation for TW. Barriers to HIV research participation included limited research opportunities, mistrust, fear of mistreatment, safety and confidentiality, competing priorities and HIV stigma. Facilitators to HIV research participation were peer involvement and engagement, monetary and non-monetary incentives, flexibility and choices, multiple modalities and methods, and transcenteredness.

Conclusion It is critical to address the social and economic vulnerabilities surrounding HIV research participation for TW. Results from this study can inform the design and implementation of gender-affirming and culturally tailored approaches to HIV research with TW.
Strengths and limitations of this study

- The study is prone to selection bias as participants were required to use an online platform for participation.

- We were not able to link the specific demographic characteristics of participants with their focus group narratives due to the nature of the audio recording and the focus group discussion.

- Results from this study can inform the design and implementation of gender-affirming and culturally tailored approaches to HIV research with transgender women.

\section{INTRODUCTION}

In the USA, transgender women (TW) are highly burdened by HIV infection with an estimated $21.7 \%$ HIV prevalence (meta-analysis), a 34.2-fold increased odds of HIV relative to the general adult population. ${ }^{1}$ Research is needed into the drivers of the HIV epidemic and specific vulnerabilities facing TW to identify optimal targets for interventions to reduce HIV disparities for this key population. ${ }^{2}$ While some longitudinal research has been implemented with $\mathrm{TW}^{3}{ }^{4}$ assembling a large multisite longitudinal cohort study represents a crucial step towards advancing the scientific evidence-base about HIV incidence and predictors of HIV seroconversion for TW. To effectively recruit, enrol and retain a multisite cohort of HIV risk among TW, it is important to first identify and understand barriers and facilitators to research participation for this population.

Factors shaping research participation for marginalised communities are multifactorial. ${ }^{5}$ While existing studies have provided a broad overview of general facilitators and barriers to TW's engagement in research, ${ }^{27-9}$ 
they have not explicitly delved into specific mechanisms for facilitating participation of TW in longitudinal study designs for HIV research. Further, to our knowledge, perceived acceptability of in-person and online methods for cohort creation have not yet been assessed. Several studies have demonstrated that it is feasible to recruit, enrol and retain 'hard to reach' populations in HIV research using online methods. ${ }^{10}{ }^{11}$ Online methods can yield diverse samples of transgender individuals who may not otherwise be reached with in-person methods. ${ }^{10}$ One study on black young men who have sex with men (MSM) and TW ages 16-21 in D.C. reported the use of contemporary technology as a key facilitator to research recruitment and participation. However, even using online methods, participants stressed the need for transparency in communication of study procedures and recommended using peer recruitment techniques to facilitate transgender participation. ${ }^{12}$

This study sought to characterise TW's first-hand experiences participating in research, perceptions of HIV research and actual and perceived barriers and facilitators to HIV research participation, including a longitudinal cohort and study designs using combined in-person and online methods. The findings can be used to inform engagement of TW into longitudinal HIV research studies, including observational cohorts and interventional trials.

\section{METHODS}

\section{Participants and procedures}

This formative research was conducted to inform the enrolment of a multisite, longitudinal cohort of TW in the eastern and southern USA targeting six high-risk cities: Baltimore, Washington DC, Boston MA, New York NY, Atlanta GA and Miami FL. The goal of the cohort is to characterise risk factors for HIV infection, access to biobehavioural HIV prevention methods and linkage to care for those who HIV seroconvert for the purposes of informing evidence-based and acceptable interventions to reduce HIV incidence for TW.

Between August 2017 and January 2018, five focus groups were conducted in English $(n=33)$ and two in Spanish $(n=8)$. Recruitment used a mixed format of technology and non-technology infused methods. Technology-infused methods included social media, such as Facebook, and websites such as Craig's List. Nontechnology methods included peer referrals, referrals from study staff and clinic-based referrals. Maximum variation sampling was used to enrol participants across a wide range of race, ethnicity, age, geographic residence and gender transition/affirmation. Sampling continued until data saturation occurred wherein redundancy was identified in the data being collected. ${ }^{13}$

Focus groups used synchronous computer-mediated communication (CMC; 'online focus groups'). ${ }^{14} \mathrm{~A}$ CMC focus group method was selected to enable the convening of TW participants across the six cities, and to overcome challenges documented in prior research with TW such as costs and logistics associated with transportation to and from a physical locale. ${ }^{9}$ Focus groups comprised participants from across all six research sites. Prior to enrolment, candidate participants were screened for eligibility: TW based on the two-step method ${ }^{15}$, ages $\geq 18$ years and reside in one of the six metropolitan areas or outlying regions. Participants were verbally consented in the language of their choice (English or Spanish) and had the option to use video or upload a photograph if they preferred to be seen by other participants. Discussions were led by one to two facilitators, used audio communication to avoid delays associated with typed CMC and followed the best practices set forth for CMC qualitative research. ${ }^{1116}$ A professional online meeting provider was used to maximise security, provide audio recording and offer telephone call-in options for participants who did not have internet access. Groups were facilitated by two experienced research staff who were either members of the transgender community or were cisgender women allies.

At total of 74 individuals were screened for eligibility, 70 were deemed eligible and among them 41 (58.6\%) participated. Among the $29(41.4 \%)$ that did not participate, $16(55 \%)$ did not attend because they either forgot or had scheduling conflicts, 4 (14\%) had technology challenges and $9(31 \%)$ did not partake for unknown reasons. Participants received a US $\$ 40$ incentive for focus group completion.

Boston Children's Hospital, the research partner, ceded review to the Johns Hopkins School of Public Health as the prime recipient of the funding.

\section{Patient and public involvement}

A Community Advisory Board (CAB) consisting of TW from the six study locations (New York City, Miami, Baltimore, Washington D.C, Boston, Atlanta) provided a community review approving the study.

\section{Measures}

A semistructured discussion guide was used during data collection. The domains outlined were: general knowledge, attitudes, perceptions on sexual health research for TW, research participation and perspectives, recruitment, study materials and communication, and study retention. Several cross-cutting themes arose throughout the coding: safety, general confidentiality concerns, respectful treatment, study staff training and involvement of transgender peers in research. Probes within each domain sought to elicit deeper understanding of each topic area.

\section{Data analysis}

Qualitative analyses were iterative in nature, bringing in results and new questions raised from earlier focus group discussions (FDGs). An iterative, analytic method followed Crabtree and Miller's five-step approach to qualitative interpretation: (1) describing, (2) organising, (3) connecting, (4) corroborating and 5) representing. 


\begin{tabular}{lc}
$\begin{array}{l}\text { Table } 1 \\
\text { participants }(\mathrm{n}=41)\end{array}$ \\
\hline Demographic characteristic & Participants N (\%) \\
\hline Mean age (SD, range) & $41.1(13.6,21-70)$ \\
Race & $14(34.1 \%)$ \\
\hline White & $14(34.1 \%)$ \\
Black & $2(4.9 \%)$ \\
Asian & $11(26.8 \%)$ \\
\hline More than one race or other & $11(26.8 \%)$ \\
Hispanic/Latina & \\
City & $7(17.1 \%)$ \\
Atlanta & $9(22.0 \%)$ \\
Baltimore & $4(9.8 \%)$ \\
Boston & $5(12.2 \%)$ \\
\hline Miami & $5(12.2 \%)$ \\
\hline New York City & $11(26.8 \%)$ \\
\hline Washington, D.C. &
\end{tabular}

Regular debriefing meetings were held with focus group facilitators to identify preliminary findings and facilitate an iterative data analysis. ${ }^{17}$ An initial template of codes was developed based on core domains described above. Codes were applied to deidentified FDG transcripts using NVivo software by three independent analysts. The analysts each identified new codes as they emerged. Summaries of major themes and distinctions were developed across subgroups. Corroboration included discussing preliminary findings with the CAB.

\section{RESULTS}

Table 1 highlights the sample's demographic characteristics by individual focus group. The mean age of the sample was 41.1 years $(\mathrm{SD}=13.6$, range $=21-70)$. The majority identified as people of colour: $34 \%$ black, $27 \%$ more than one race, $5 \%$ Asian and $34 \%$ white. Ethnically, $29 \%$ classified themselves as Hispanic/Latina. Geographic representation was well dispersed with $17 \%$ from Atlanta, 22\% Baltimore, $10 \%$ Boston, 12\% Miami, 12\% New York City, and $27 \%$ from Washington D.C.

Table 2 provides numbered quotes from select participants in the FDGs in the following results.

\section{Research participation}

Approximately one-third reported prior first-hand involvement in research. Of these, most participated in studies that asked them about their gender identity and being transgender in the context of research on discrimination and HIV risk, prevention and/or treatment. Most TW expressed mixed sentiments about prior research participation, with varied experiences (Quote\#1). Among those who had participated in HIV research, there were critiques about the length of surveys, the repetitiveness of questions and the content of items. For some, questions were too personal to be answered; for others, survey questions were too shallow or 'not relevant' to their everyday lives. Spanish-speaking focus group participants mentioned experiences with inaccurate translations in consent forms and survey instruments.

\section{Barriers to participating in HIV research}

Barriers to HIV research participation encompassed six themes largely related to social and economic vulnerabilities: limited opportunities, research mistrust, fear of mistreatment, safety and confidentiality, competing economic priorities and HIV stigma.

\section{Limited opportunities}

Participants generally described willingness to participate in HIV research. However, participants described the invisibility of TW in HIV research due to the common practice of collapsing TW into the category of MSM. TW perceived limited opportunities for research participation specific to TW (Quote \#2). Some TW reported being excluded from research studies due to being transgender (Quote \#3). Where opportunities for participation were available, TW highlighted the narrow topics for participation. TW also were interested in studies on access to healthcare, mental health, intimate partner violence, long-term effects of hormone therapy and careers and employment.

\section{Research mistrust}

Research mistrust was often described in relation to historically being marginalised and ignored by medical communities (Quote \#4). TW perceived that researchers withhold information and do not disclose "what the value will be of their being researched' and 'what you would do with the information that you get' (FGD\#4). Feeling 'used' by researchers was commonly discussed in not hearing about findings from research they participated in (Quote \#5). Several participants discussed wanting to avoid 'that guinea pig feeling' (FGD\#4). Lack of clarity and transparency in communication by researchers contributed to TW mistrust. One participant raised this issue specifically about recruitment: "Even with this study, I know there's non-binary people who weren't sure based on the language that was used in the announcement, if they were eligible to take this survey because they're on the transgender spectrum but they don't identify as women" (FGD\#1). Lack of specificity about inclusion and exclusion criteria heightened mistrust, including whether 'transgender' research studies are open to people with both binary (eg, female) and non-binary (eg, genderfluid) identities.

\section{Fear of mistreatment}

Fear of mistreatment, or anticipating experiences of prejudice and discrimination, was described as a barrier to research participation. Several participants reported avoiding HIV research because someone they knew had a negative experience (Quote \#6). The term 'triggered' was used by several participants when describing 
Table 2 Selected participant quotes: barriers and facilitators to research participation for transgender women

\begin{tabular}{llll}
\hline Theme Quote \# Quote Focus group \# \\
\hline Barriers
\end{tabular}

Research participation $1 \quad$ "I have participated in different studies over the course of a few years and what I find is 5 that most of the studies are asking primarily the same questions for the trans community and everything is based around stigma and medications and things like that, but there are so many other things and barriers that I feel like that could be addressed."

$\begin{array}{lcl}\text { Limited opportunities } & 2 & \begin{array}{l}\text { "I personally think that it's just a lack of availability. There's just not too much research } \\ \text { being done, and if there is, it's just not publicized enough." }\end{array} \\ & 3 & \begin{array}{l}\text { "I couldn't find any [research] that I qualified for. There were a lot of, like, gendered things } 1 \\ \text { involved...and so I realized that that wasn't really a path that I could really take unless it } \\ \text { was specifically for, like, trans people." }\end{array} \\ \text { "Until recently there just wasn't any motivation to study this kind of thing ... Like, nobody } 4 \\ \text { was willing to listen. Like, in the medical community, I mean." }\end{array}$

$\begin{array}{cl}\text { Fear of mistreatment } 6 \quad \text { "I know of someone who did a research study specifically targeted towards trans women } & 1 \\ \text { who came out of id identifying it as a traumatizing experience... she was misgendered } \\ \text { constantly by all of the staff that were interacting with her ... it got to a point where she } \\ \text { felt incredibly uncomfortable around everyone, but stayed with it to get through the end } \\ \text { of the study because she was already too far in and didn't want to, like, A, needed the } \\ \text { money, and then B, felt too uncomfortable to, like, say something." }\end{array}$

Safety and $\quad 7 \quad$ "There's some neighborhoods in the city where I would not be welcome, and there's 1 confidentiality some neighborhoods in the city where I can just hang out and do my thing. You know, it needs to be somewhere that the participants would consider to be a safe neighborhood for trans people to be in."

\begin{tabular}{|c|c|c|c|}
\hline \multirow[t]{3}{*}{$\begin{array}{l}\text { Competing economic } \\
\text { priorities }\end{array}$} & 8 & $\begin{array}{l}\text { "Well I mean until you have adequate housing and a job, I mean you're a little less likely } \\
\text { to want to enter into any [research] groups or things like that and everything." }\end{array}$ & 5 \\
\hline & 9 & $\begin{array}{l}\text { "Van a dejarse de ganar no } \$ 800 \text {, por ejemplo } \$ 600 \text {, salgo perdiendo. No Hello! Me voy" } \\
\text { (English translation: "They will stop earning } \$ 800 \text {, and for example will earn } \$ 600 \text {. I lose. } \\
\text { No hello! I am going.") }\end{array}$ & 7 \\
\hline & 10 & $\begin{array}{l}\text { "It's hard trying to get around with transportation around different places if you don't have } \\
\text { a car or either if you're riding the train, you still need money to get on the train. So I don't } \\
\text { want to go from one place to all the way to NIH to get } \$ 20 \text { dollars. That's really not worth } \\
\text { the time." }\end{array}$ & 2 \\
\hline HIV stigma & 12 & $\begin{array}{l}\text { "Not all of us are forced into the sex trade and having to give up our bodies and } \\
\text { everything in order to transition. That is where a lot of the HIV resides, is in people that } \\
\text { have-are being forced into that and that is what needs to be addressed, not the resultant } \\
\text { effect if them getting HIV but why did they have to get there in the first place? And if } \\
\text { you're not going to address that, I don't want to be part of this!" }\end{array}$ & 4 \\
\hline
\end{tabular}

13 "Como cuando usted está haciendo la encuesta, no hay suficiente confianza y mienten 6 en cuanto a cómo a enfermedades de transmisión sexual y hay gente que cuando termina la encuesta le dice a la persona que, digamos que le va a tomar la muestra de sangre, que donde pueden pasar consulta, o sea son cosas que se dan por falta de confianza." (English translation: "Like when you are doing the survey, there is not enough trust and they lie about how to sexually transmitted diseases and there are people who when the survey is finished tell the person that, let's say they are going to take the blood sample, that where they can pass query, that is to say they are things that are given by lack of trust.")

Facilitators
Peer engagement $\quad 14 \quad \begin{aligned} & \text { "If I were to walk into, like, a building or an organization or a place of business and the } \\ & \text { people dealing-like at least some of the people dealing with me are trans, that raises my } \\ & \text { comfort level times, like, a million." }\end{aligned}$
"One of the interviewers that I had for several of the different interviews that I came in
for, she was a trans woman. That was absolutely the best because I felt completely
comfortable sharing everything with her."


Table 2 Continued

\begin{tabular}{lcl}
\hline Theme & Quote \# & Quote \\
\hline $\begin{array}{l}\text { Monetary and non- } \\
\text { monetary incentives }\end{array}$ & 17 & $\begin{array}{l}\text { "You can get a lot of people involved when you tell them it's a coin involved. Some type } \\
\text { of incentive to make you want to come and do that." }\end{array}$ \\
& 18 & $\begin{array}{l}\text { "I think that - I don't know how I want to word this -a lot of trans people just want to tell } \\
\text { their story... I think that that's part of why we will jump on opportunities to meet up with } \\
\text { other trans people and will meet up in communities and will - whether those communities } \\
\text { are physical or digital. And, so, making it clear that part of why you're there to listen as far } \\
\text { as you want to have somebody involved in your research is because you really want to } \\
\text { take their story and to work with it and to get out of it and to help other people." }\end{array}$
\end{tabular}

\begin{tabular}{|c|c|c|c|}
\hline Flexibility and choices & 19 & $\begin{array}{l}\text { "I think that having as many options as possible, obviously is the best route. But I think, } \\
\text { obviously, like a lot of trans people would have, like, reservations about interacting with } \\
\text { people specifically about their transness. And so I think the online thing is great, but at } \\
\text { the same time, for me, it's the phone call - like it was like, 'Email or phone call?' and I } \\
\text { was like, 'Phone call,' because I'll be able to find out immediately if, like, this is a thing I } \\
\text { can do." }\end{array}$ & 1 \\
\hline $\begin{array}{l}\text { Multiple modalities } \\
\text { and methods }\end{array}$ & 20 & $\begin{array}{l}\text { "I think having an online one [screener for eligibility] would be less intimidating for a lot of } \\
\text { people." }\end{array}$ & 1 \\
\hline Transcenteredness & 22 & $\begin{array}{l}\text { "Right at the beginning, when they're trying to figure out if they want [you] or not, they'll } \\
\text { have their list of things that you need to mark on to say what you are, your identity for this } \\
\text { particular study. And if that's worded in such a way that it only fits binaries, it basically } \\
\text { starts jamming you into these boxes, you can pretty easily tell that [it) isn't going to be a } \\
\text { trans-friendly survey." }\end{array}$ & 1 \\
\hline
\end{tabular}

potential research participation. Fears of rejection or exclusion were also discussed in the context of meeting or not meeting eligibility criteria for research studies.

\section{Safety and confidentiality}

Concerns about safety and confidentiality emerged. Physical safety was discussed in relation to the location of study visits (Quote \#7). Confidentiality concerns largely focused on being 'outed' as transgender due to participating in a research study for TW. One participant distilled this theme: "It all dials right back to safety and feeling secure, because why put yourself in a situation that could possibly be detrimental to yourself?" (FGD\#4). Spanish focus group participants discussed immigration issues as a barrier to participation in HIV research, specifically safety concerns related to having an undocumented status.

\section{Competing economic priorities}

TW perceived that researchers do not 'know' or 'understand' the realities facing TW communities, especially those related to poverty. Many TW described competing economic priorities, such as securing stable housing and food security (Quote \#8). Those who were employed prioritised their job and did not want to jeopardise it. Not being adequately incentivised/reimbursed emerged as a theme. Participants lacked motivation to participate when incentives were not adequate. This was especially true for TW engaged in sex work because of the potential to make more money for the same amount of time (Quote \#9). In general, TW felt that incentives/reimbursements do not take into account the time it takes to commute to/from a study visit. This was highlighted in discussing transportation as a barrier (Quote \#10).

\section{HIV stigma}

Participants discussed the high levels of HIV stigma in the TW community. HIV stigma was felt to impact participation in HIV research (Quote \#11). TW articulated the importance of designing HIV research for TW with consideration for HIV stigma or "you'll run the people off" (FGD\#5). One participant responded very negatively about HIV research, illustrating the HIV stigma within the community and the ways that the constant focus on HIV in TW communities perpetuates both TW marginalisation and HIV stigma (Quote \#12). Participants also cautioned how stigma pertaining to sexual health may influence survey responses, particularly accuracy of answers: "If it's about sexual health, you may have people who aren't willing to like, be completely truthful about things because of stigmas and things like that" (FGD\#1). Trust emerged as vital to combat the barrier of stigma in sensitive health topics related to sexuality (Quote \#13).

\section{Facilitators to TW research participation}

Facilitators to research participation were peer engagement, monetary and non-monetary incentives, flexibility and choices, multiple modalities and methods, and transfriendliness.

\section{Peer engagement}

Peer engagement was a facilitator to HIV research participation across all focus groups (Quote \#14). One participant described an empowering experience she had in HIV research with a staff member who was a TW 
herself (Quote \#15). Interacting with peers increased perceived safety due to the shared experience of being transgender (Quote \#16). Having peers meaningfully involved as paid research staff and/or members of a $\mathrm{CAB}$ seemed to be a strong indicator for a participant's willingness to be recruited for an HIV study and participate in a longitudinal research study.

\section{Monetary and non-monetary incentives}

Monetary incentives were a facilitator to HIV research participation (Quote \#17). Cash incentives had the highest acceptability, followed by gift cards. Waiting to receive an incentive after participating in a study, for example, having it sent via mail, was not acceptable. Nonmonetary incentives were also discussed. The feeling of being part of a broader community, and to contributing one's 'voice' and 'story' arose as a theme (Quote \#18). Other non-monetary incentives mentioned were social events, gifts, poststudy resources such as linkage to hormones and free medical care including HIV testing.

\section{Flexibility and choices}

Flexibility arose as an important principle of working with TW and facilitating research participation. This was mentioned in relation to flexible scheduling for appointments and study visits, and the ability to reschedule quickly. Drop-in study visits were also suggested. Related to flexibility was the topic of offering options and choices for TW in study protocols and procedures. One participant described this when discussing preferences for telephone-based or onlinebased screening for study eligibility (Quote \#19).

Multiple modalities and methods (eg, in person and online)

The importance of multiple modalities for HIV research participation arose in relation to discussing perceived acceptability of online and in-person methods. For some, online methods were seen to facilitate participation (Quote \#20). For others, there was a preference for in-person participation. There was awareness across all focus groups that access to the internet and technology literacy were challenges for some subgroups of TW vulnerable to HIV, particularly for economically disadvantaged TW and/or TW of colour (Quote \#21). There was an emphasis on the need for multiple modalities and methods to reach different subsets of TW communities. Age-related considerations emerged with younger TW most comfortable with online technology and methods.

\section{Transcenteredness}

Participants described reading cues in the environment to assess the extent to which the research was going to be 'transfriendly' (Quote \#22). TW believed that respectful treatment can only occur when the study team members are trained adequately. Not misgendering participants, using correct names, and displaying cultural humility were areas recommended for training. Transcenteredness was often linked to the cross-cutting theme of involving peers in research, as peers were perceived to understand and have lived similar experiences. Several TW also pointed out that even peers need appropriate training to treat participants with respect, including how to navigate boundaries and potential challenges they may face with peer-to-peer research interactions.

\section{DISCUSSION}

This study found that multiple factors shape HIV research participation for TW, particularly social factors such as stigma and economic issues including competing priorities, corroborating findings from prior research with TW. ${ }^{79}$ While TW share some barriers and facilitators to research participation with other marginalised groups,${ }^{56}$ results highlight the importance of leveraging both social (eg, peer engagement) and economic (eg, incentives) factors to facilitate TW research participation. Specifically, gender-affirming and culturally tailored approaches to HIV research will need to collaborate with TW communities to address barriers and enhance facilitators for HIV research participation, especially those which are uniquely experienced by TW. Further research is warranted to understand the weight or impact that specific barriers and facilitators have on research participation for TW in order to overcome them.

Scarcity of transgender-specific research and restricted range of study topics are perceived as social exclusion by TW. Previous discrimination experienced in medical contexts fuels mistrust of research and fear of mistreatment for TW. Medicine has historically pathologised and stigmatised TW health needs. In HIV research, the legacy of mistrust is specific to TW having been categorised as MSM. ${ }^{18-20}$ TW did not trust researchers to consider their specific safety and confidentiality concerns such as their physical safety in terms of geographic location of research sites (potential exposure to violence) and emotional safety and confidentiality (concerns of being 'outed'). The fear of being outed is closely linked to HIV stigma and also emerged as a barrier to research participation, consistent with prior research. ${ }^{9}$ Specifically, TW in this study did not want to be perceived by others in their network as HIV positive or at risk for HIV due to their participation in HIV research. Therefore, asking about health and wellness beyond HIV, and having different surveys for varied health domains, was suggested as strategies to minimise this barrier and increase TW research participation.

TW perceived a lack of transparency and clarity in communication from researchers which heightened community mistrust. Non-transparency was mentioned in relation to defining study eligibility and substantiates previous research. ${ }^{7-9} 21$ Presenting information about study inclusion and exclusion criteria in a clear manner that is respectful is crucial for building trust. Further, the lack of access to the results of research that TW participate in has raised suspicion among TW communities of researcher motives. Mistrust of researchers is 
more than failing to disseminate findings back to TW communities. Rather, there is a perception that other populations, such as MSM, have largely benefitted from the research that TW participate in while TW do not, given the ongoing absence of transspecific interventions. Findings suggest that building trust between TW and medical and research communities will take time and will ultimately be cultivated with transparent study procedures that address safety and confidentiality concerns of TW.

In addition to social barriers, economic vulnerabilities (eg, housing, food, transportation needs) may prevent research participation for TW, consistent with other marginalised communities. ${ }^{5}{ }^{6}$ As found in prior TW research, ${ }^{2}$ monetary incentives (ideally cash) for participation and for transportation are facilitators to research engagement for most TW. However, in the context of economic marginalisation, and the potential for higher earnings in sex work for some TW, incentives not appropriately tailored to TW may not be enough to overcome competing priorities and encourage research participation. These economic barriers suggest the need to tailor incentives for TW to enhance participation in HIV research to ensure adequate compensation.

Facilitators to research participation identified are those factors which address the social and economic contexts facing TW. 'Transcenteredness' emerged as a basic and important tenet. TW wanted to be at the centre of the research enterprise, rather than having to fit into a rigid system which lacks knowledge of the community's culture and values. Against this backdrop, the current study identified flexibility and choice as facilitators to TW research participation. The ability to choose whether and how to participate and interact with researchers (eg, in person or online modalities) increased feelings of safety and trust. Flexibility in scheduling (eg, easy rescheduling, variety of hours and days of operation) can be a signal to TW that researchers are respectful of TW time and needs. Having increased control over their experiences in the study may be an important facilitator to participation. ${ }^{22}$ 'Choice' emerged as a central theme for TW in this study (eg, being able to choose incentives, electing how to interface with the study team). A hallmark of informed consent is the voluntary nature of research participation. Maximising the extent to which TW feel control over their experiences in the research setting by having choices will facilitate participation.

Participants discussed peer engagement as vital to TW research participation, corroborating previous studies. ${ }^{7-9}$ Examples were engaging TW peers in recruitment, collaborating with local transgender communitybased organisations, hiring TW as staff members and engaging a $\mathrm{CAB}$ to guide the research. Peer involvement was felt to provide a more affirming environment, ultimately increasing comfort and building trust. Social events for TW were endorsed as non-monetary incentives for research participation. Peers' negative experiences with stigma and mistreatment (eg, misgendering) in research were a deterrent to participation. This finding highlights the role of social networks in TW research participation, both as potential facilitators and potential barriers. Involving TW communities in the study, including as paid staff, is important to ensure that multiple community perspectives are captured.

TW emphasised the need for transcompetent research environment, consistent with prior research. ${ }^{7-9} 21$ Transgender people often 'scan for safety' meaning look for cues that indicate safety and competency to them. Hands-on training for research staff about transgender health needs, stigma and culture (eg, names, pronouns, dead naming, misgendering) is essential. Staff members need to understand TW lived experiences, including barriers and facilitators to research participation. Training should be given to staff in how to sensitively communicate qualifications to participate in a research study. Research scripts and procedures can be perceived as microaggressions or as perpetuating stigmas because they appear rigid and inflexible. For TW, engaging in research, even just being screened for eligibility, comes with the possibility of rejection and exclusion. If an individual is not eligible to participate, having alternate activities to engage in (eg, other studies to refer to, community referral programme where TW can receive stipends) is important. To encourage TW communities to participate in research, it is crucial to gain trust, ensure safety and address confidentiality concerns.

There are several limitations to this research. The study is prone to selection bias as participants were required to use an online platform for participation. While the proportion of those who reported technological challenges as a barrier to participation was low, it is possible that those TW who are less comfortable or inexperienced using this technology may have been missed. We were not able to link the specific demographic characteristics of participants with their focus group narratives due to the nature of the audio recording and the FDG. At times, it was difficult to discern what a participant was saying due to overlapping conversations. The same facilitator was not present for all group discussions; while all facilitators were trained to ensure consistency, there is the possibility that this potentially increased variability in questions and probes across discussions. Finally, there was no recording of non-verbal reactions or cues for field notes.

\section{CONCLUSION}

Longitudinal studies, whether observational or interventional, are a powerful research design to study exposures and outcomes over time among TW. To conduct these studies, it is important to know what methods are acceptable to enrol and retain TW participants. It is an imperative to safeguard longitudinal studies against threats to internal and external validity, such as introduction of bias related to selection and to differential loss to follow-up. Understanding TW experiences and 
perceptions of research participation can provide valuable insights to inform strategies to reduce potential biases and contribute to the evidence-base of HIV risks and resiliencies.

HIV is not equally distributed across all TW: TW of colour and of economic disadvantage are particularly susceptible. Thus, refining strategies to reach highest risk groups is vital. The multiple social and economic barriers to research participation found in this study can inform gender-affirming and culturally tailored approaches to HIV research with TW. Researchers must consider context and the ways that stigma and other vulnerabilities manifest for TW in the research environment. Anticipated stigma-wherein stigmatised people expect to experience prejudice and discrimination ${ }^{23}$ - has been shown to lead to avoidance of healthcare among transgender people ${ }^{24}$; the current study extends anticipated stigma to avoidance of HIV research settings for TW. Findings from this study can be leveraged for future HIV research to mitigate common barriers and enhance facilitators to TW research participation.

\section{Article's summary}

This study examines the specific mechanisms for facilitating participation of TW in longitudinal study designs for HIV research.

Acknowledgements The authors would like to express their gratitude to the transgender women who took part in this study. This study would not be possible without their participation.

Contributors SR, EC and ALW were involved in the original design of the study and recruitment of participants, and shared responsibility of facilitating the focus group discussions. HG-D, EJ-C and AC coded the qualitative data, and all authors participated in reviewing the codes and modifications of the coding process. AC synthesised the results for the manuscript and SR wrote the manuscript for all authors to review. All authors revised the final manuscript and approved its submission.

Funding Research reported in this publication was jointly supported by the National Institute of Allergy and Infectious Diseases, the National Institute of Mental Health, and the National Institute of Child Health and Human Development of the National Institutes of Health under Award Number UG3Al133669 (awarded to ALW and SLR). The content is solely the responsibility of the authors and does not necessarily represent the official views of the National Institutes of Health.

Competing interests None declared.

Patient consent for publication Not required.

Ethics approval Johns Hopkins School of Public Health provided the Institutional Review Board approval.

Provenance and peer review Not commissioned; externally peer reviewed.

Data availability statement All data relevant to the study are not available to protect participant anonymity and privacy.

Open access This is an open access article distributed in accordance with the Creative Commons Attribution Non Commercial (CC BY-NC 4.0) license, which permits others to distribute, remix, adapt, build upon this work noncommercially, and license their derivative works on different terms, provided the original work is properly cited, appropriate credit is given, any changes made indicated, and the use is non-commercial. See: http://creativecommons.org/ licenses/by-nc/4.0/.

\section{ORCID iD}

Aeysha Chaudhry http://orcid.org/0000-0001-5367-0217

\section{REFERENCES}

1 Baral SD, Poteat T, Strömdahl S, et al. Worldwide burden of HIV in transgender women: a systematic review and meta-analysis. Lancet Infect Dis 2013;13:214-22.

2 Poteat T, Scheim A, Xavier J, et al. Global epidemiology of HIV infection and related Syndemics affecting transgender people. $J$ Acquir Immune Defic Syndr 2016;72 Suppl 3:S210-9.

3 Nuttbrock L, Bockting W, Rosenblum A, et al. Gender abuse and incident HIV/STI among transgender women in New York City: buffering effect of involvement in a transgender community. AIDS Behav 2015;19:1446-53.

4 Nuttbrock L, Bockting W, Rosenblum A, et al. Gender abuse, depressive symptoms, and HIV and other sexually transmitted infections among male-to-female transgender persons: a three-year prospective study. Am J Public Health 2013;103:300-7.

5 George S, Duran N, Norris K. A systematic review of barriers and facilitators to minority research participation among African Americans, Latinos, Asian Americans, and Pacific Islanders. Am J Public Health 2014;104:e16-31.

6 Richardson S, Seekaew P, Koblin B, et al. Barriers and facilitators of HIV vaccine and prevention study participation among young black MSM and transwomen in New York City. PLoS One 2017;12:e0181702.

7 Andrasik MP, Yoon R, Mooney J, et al. Exploring barriers and facilitators to participation of male-to-female transgender persons in preventive HIV vaccine clinical trials. Prev Sci 2014;15:268-76.

8 Siskind RL, Andrasik M, Karuna ST, et al. Engaging transgender people in NIH-funded HIV/AIDS clinical trials research. J Acquir Immune Defic Syndr 2016;72 Suppl 3:S243-7.

9 Owen-Smith AA, Woodyatt C, Sineath RC, et al. Perceptions of barriers to and facilitators of participation in health research among transgender people. Transgend Health 2016;1:187-96.

10 Miner $\mathrm{MH}$, Bockting WO, Romine RS, et al. Conducting Internet research with the transgender population: reaching broad samples and collecting valid data. Soc Sci Comput Rev 2012;30:202-11.

11 Wilkerson JM, lantaffi A, Grey JA, et al. Recommendations for Internet-based qualitative health research with hard-to-reach populations. Qual Health Res 2014;24:561-74.

12 Glick SN, Houston E, Peterson J, et al. Understanding engagement in HIV risk and prevention research among black young men who have sex with men and transgender women in the district of Columbia. LGBT Health 2016;3:308-13.

13 Saunders B, Sim J, Kingstone T, et al. Saturation in qualitative research: exploring its conceptualization and operationalization. Qual Quant 2018;52:1893-907.

14 Wirtz AL, Cooney EE, Chaudhry A, et al. Computer-Mediated communication to facilitate synchronous online focus group discussions: feasibility study for qualitative HIV research among transgender women across the United States. J Med Internet Res 2019;21:e12569.

15 Reisner SL, Conron KJ, Tardiff LA, et al. Monitoring the health of transgender and other gender minority populations: validity of natal sex and gender identity survey items in a U.S. national cohort of young adults. BMC Public Health 2014;14:1224.

16 Reid DJ, Reid FJ. Online focus groups. International Journal of Market Research 2005;47.

17 Crabtree BF, Miller WL. Doing qualitative research. Thousand Oaks, CA: Sage Publications, 1999.

18 Sevelius JM, Keatley J, Calma N, et al. 'I am not a man': Transspecific barriers and facilitators to PrEP acceptability among transgender women. Glob Public Health 2016;11:1060-75.

19 Poteat T, German D, Flynn C. The conflation of gender and sex: gaps and opportunities in HIV data among transgender women and MSM. Glob Public Health 2016;11:835-48.

20 Perez-Brumer AG, Oldenburg CE, Reisner SL, et al. Towards 'reflexive epidemiology': Conflation of cisgender male and transgender women sex workers and implications for global understandings of HIV prevalence. Glob Public Health 2016;11:849-65.

21 Fisher CB, Fried AL, Desmond M, et al. Facilitators and barriers to participation in PreP HIV prevention trials involving transgender male and female adolescents and emerging adults. AIDS Educ Prev 2017;29:205-17.

22 Miller Carol T. Kaiser Cheryl R. a theoretical perspective on coping with stigma. Journal of Social Issues 2002;57:73-92.

23 Pescosolido BA, Martin JK. The stigma complex. Annu Rev Sociol 2015;41:87-116.

24 James SE, Herman JL, Rankin S, et al. The report of the 2015 U.S. transgender survey. Washington, DC: National Center for Transgender Equality, 2016. 